\title{
Disciplina de Atenção em saúde: aprendizado interprofissional e com o SUS
}

Najara Barbosa da Rocha, Adriana Lenita Meyer Albiero, Cristiano Fagundes, Sonia Satie Sakamoto Asanome, Davi Aguiar Silva Machado

\section{Resumo}

A formação interprofissional é um grande desafio para melhorar a resolutividade na atenção primária e para tanto, é importante que os cursos de graduação busquem a vivência desta prática durante a formação. Este trabalho teve o objetivo de relatar a experiência dessa disciplina de Atenção em Saúde da Universidade Estadual de Maringá nos cursos da área da saúde. A disciplina de Atenção à Saúde I é uma proposta pioneira e inovadora da Universidade Estadual de Maringá (UEM), inserida em 2015, comum no currículo do primeiro ano de sete cursos da área da saúde: Biomedicina, Educação Física, Enfermagem, Farmácia, Medicina, Odontologia e Psicologia. Os estudantes são distribuídos em grupos multiprofissionais de 10 a 11 alunos, orientados por um tutor (docente) e auxiliado por um preceptor (profissional do serviço de saúde). O objetivo da disciplina é conhecer a organização e dinâmica de funcionamento dos serviços no Sistema Único de Saúde (SUS) e compreender as ações desempenhadas sobre educação, promoção e recuperação da saúde, prevenção de doenças e melhoria da qualidade de vida da população. Introdução As Diretrizes Curriculares Nacionais que fundamentam os cursos da área na saúde no Brasil esclarecem os princípios, fundamentos, condições e procedimentos na formação profissional, como desenvolvimento de habilidades e competências de atenção à saúde, tomada de decisões, comunicação, liderança, administração/gerenciamento e educação permanente. Assim, as universidades são responsáveis pela qualificação de futuros profissionais e deve assegurar que a prática profissional seja realizada de forma integrada e contínua com as demais instâncias e profissionais do sistema de saúde, sendo capaz de pensar criticamente, de analisar os problemas da sociedade e de procurar soluções para os mesmos1. A formação dos profissionais da atenção deve levar em conta todos estes aspectos embutidos no princípio de integralidade assegurado por lei no Sistema Único de Saúde, que envolvem questões relacionadas à humanização da atenção, ao conceito ampliado de saúde, à educação permanente em saúde, ao trabalho em equipe interprofissional, entre outros. A educação interprofissional tem sido apontada como meio de melhorar a colaboração e a prestação de serviços, em cenários de prática, na qual estudantes de diferentes profissões aprendem, um com o outro, podendo desenvolver formas de trabalhar em conjunto para melhorar os serviços oferecidos à população3. No Brasil, o ensino interprofissional apresenta-se atualmente como a principal estratégia para formar profissionais aptos para o trabalho em equipe e prática essencial para a integralidade no cuidado em saúde4. Nesta diretriz, foi proposta a disciplina de Atenção em Saúde, comum no currículo dos cursos da área da saúde da Universidade Estadual de Maringá (UEM): Biomedicina, Educação Física, Enfermagem, Farmácia, Medicina, Odontologia e Psicologia. A disciplina tem como estratégias: metodologia ativa, trabalho em equipe e o contato com as necessidades de saúde da população da região de Maringá e com o Sistema Único de Saúde (SUS). Objetivos Este trabalho teve o objetivo de relatar a experiência dessa disciplina de Atenção em Saúde da Universidade Estadual de Maringá nos cursos da área da saúde. Métodos Trata-se de um relato de experiência sobre a disciplina de Atenção à Saúde que é uma proposta pioneira e inovadora da Universidade Estadual de Maringá (UEM), inserida em 2015, comum no currículo do primeiro ano de sete cursos da área da saúde: Biomedicina, Educação Física, Enfermagem, Farmácia, Medicina, Odontologia e Psicologia. Os estudantes são distribuídos em grupos multiprofissionais de 10 a 11 alunos, orientados por um tutor (docente) e auxiliado por um preceptor (profissional do serviço de saúde). O objetivo da disciplina foi conhecer a organização 
ISSN 2179-6750

e dinâmica de funcionamento dos serviços no Sistema Único de Saúde (SUS) e compreender as ações desempenhadas sobre educação, promoção e recuperação da saúde, prevenção de doenças e melhoria da qualidade de vida da população5. A metodologia de ensino-aprendizagem ativa da disciplina utilizada foi problematização, apoiada no Arco de Maguerez parte da observação da realidade e após análise, levantamento de hipóteses, elaboração de propostas e discussão de soluções para os temas e problemas encontrados e, ao final, os estudantes retornam à realidade (comunidade) com um projeto de intervenção elaborado por uma equipe multiprofissional, discutido com todos os estudantes do grupo com o objetivo de trazer melhorias à comunidade. A avaliação do graduando é centrada na mensuração das competências do eixo cognitivo, demonstrada na construção de um portfólio, com avaliações diárias dos tutores, a partir das competências desenvolvidas do eixo psicomotor e afetivo, além de uma auto-avaliação. Resultados A disciplina buscou preparar o estudante para a prática colaborativa e de educação interprofissional inserido no SUS no primeiro ano de graduação, com utilização da problematização como metodologia de ensino- aprendizagem, apoiada no Arco de Maguerez, no contexto ensino-serviçocomunidade, que partiu da observação da realidade, pontos-chave, teorização, hipótese de solução, elaboração de propostas e discussão de soluções para temas e problemas encontrados. Com a utilização da metodologia ativa de ensino-aprendizagem, sendo o professor um facilitador, a aprendizagem e a busca pelo conhecimento foi responsabilidade do aluno. Foi percebido maior grau de autonomia na tomada de decisões do cotidiano do trabalho. A avaliação do graduando foi centrada na mensuração das competências do eixo cognitivo, psicomotor e afetivo. Discussão A inserção do aluno no cenário de prática no primeiro ano estimulou o estudo pela vivência significativa do aprendizado sobre o SUS e saúde coletiva5. Por meio da metodologia ativa objetiva-se a construção de um perfil acadêmico para os profissionais da saúde com abordagens contemporâneas de formação e que considere as novas demandas exigidas pelas transformações do mundo do trabalho, tendo em vista as diversidades e complexidades dos cenários de práticas e a integração ensino-serviço2. Esta integração oportuniza experiências de aprendizagem significativas que tem resultado em melhorias nos serviços de saúde e na formação profissional. A premissa colaborativa na educação interprofissional é um aspecto importante na formação profissional, preparando-os para melhor responder às necessidades locais6. Com isso, a disciplina contribui para formação de profissionais capacitados a interagir com todas as áreas da saúde para abordagem interprofissional do usuário, integrando uma equipe com conhecimentos diversos. A disciplina tem atingido os objetivos propostos, estando em consonância com as Diretrizes Curriculares dos cursos da área de saúde, incluindo a Odontologia, que aponta para uma formação generalista, que saiba atuar em equipe, de forma humanizada, com resolutividade e que compreenda a realidade em que vive a população.

Descritores: Sistema Único de Saúde, Aprendizado ativo, Educação superior, Equipe de Assistência ao Paciente 